\title{
LITERATURA DE EXPLORAÇÕES E AVENTURAS: AS "VIAGENS EXTRAORDINÁRIAS" DE JÚLIO VERNE*
}

\section{Littérature de explorations et aventures: Les "Voyages Extraordinaires" de Jules Verne}

\author{
Oswaldo Bueno Amorim Filho \\ Doutor em Geografia (Université de Bordeaux III). \\ Prof. do Programa de Pós-Graduação em Geografia da PUC-MINAS \\ infoespa@pucminas.br
}

Artigo recebido para publicação em 21/05/08 e aceito para publicação em 30/09/08

RESUMO: O forte desenvolvimento dos estudos humanistas-culturais, na geografia mundial, nas últimas décadas facilitou um novo florescimento de uma antiga colaboração entre geografia e literatura. O presente ensaio introdutório busca resgatar uma das manifestações literárias mais próximas da geografia, ou seja, a "literatura de viagens, explorações e aventuras". Esta literatura teve seu apogeu na Europa do século XIX, especialmente na Alemanha, no Reino Unido e na França. Neste último pais, o escritor Júlio Verne é o melhor exemplo deste tipo de literatura, com sua extensa coleção das "Voyages extraordinaires". Uma análise das ligações desta coleção literária com a geografia é o principal objetivo do presente ensaio.

Palavras-chave: geografia humanista-cultural, literatura de viagens e aventuras, Júlio Verne.

RESUMÉ: La forte croissance des études humanistes-culturelles au monde, dans les dernières decennies, a provoqué une rennaissance d'une ancienne collaboration entre la géographie et la littérature. Cet essai introductoire a pour objectif recouvrer une des manifestations littéraires le plus proches de la géographie, c'est a dire, la "littérature de voyages, explorations et aventures".

Cette littérature a eu son apogée dans l'Europe du XIXème siècle, surtout en Allemagne, au RoyaumeUni et en France. Dans ce dernier pays, l'écrivain Jules Verne est le meilleur exemple de ce type de littérature, avec sa grande collection de Voyages extraordinaires. Le but de cet essai est d'analyser les connexions de cette collection littéraire avec la géographie.

Mots-clés: géographie humaniste-culturelle, littérature de voyages et aventures, Jules Verne.

\section{INTRODUÇÃO}

Nas últimas décadas e em diferentes partes do mundo, observou-se o desenvolvimento de correntes geográficas que privilegiam temas e abordagens não contemplados pelos paradigmas dominantes, sejam eles cientificistas (neopositivistas), crítico-radicais (neomarxistas) ou tecnicistas (SIG e Sensoriamentos Remotos).

\footnotetext{
* Agradeço, nesta oportunidade, ao Prof. Dr. José Flávio Morais Castro, ao mestrando, Prof. Wagner B. Batella e ao graduando, Francisco M. Cortezzi, por sua participação na elaboração material do presente texto.
} 
Dessas abordagens alternativas, fazem parte os estudos das percepções, cognições e representações do ambiente geográfico e de seus "lugares e paisagens valorizados", agrupados sob a denominação geral de "geografias humanísticas ou humanistas", com bases epistemológicas mais flexíveis, procuradas nas filosofias fenomenológicas e existencialistas.

Para os estudiosos da história do pensamento geográfico, apesar de preservarem suas especificidades, essas abordagens humanistas acabaram por se aproximar, naturalmente, da nova geografia cultural.

A geografia cultural é uma das mais antigas subdisciplinas geográficas que, de acordo com Paul Claval (França, 1995; Brasil, 1999), organizou-se originalmente como campo de conhecimento na Alemanha, nos Estados Unidos e na França, nas últimas décadas do século XIX e durante a primeira metade do século XX.

Nesses primórdios dessa geografia cultural, alguns temas recebem atenção especial de pesquisadores europeus e americanos. Entre tais temas, o maior destaque vai para as paisagens e os gêneros de vida, no âmbito da também recémorganizada geografia humana. A este respeito, assim se exprime o geógrafo francês:

"A geografia humana ocupa desde seu nascimento um lugar importante nas realidades culturais, mas as capta numa ótica reducionista: a ênfase é colocada sobre as técnicas, os utensílios e as transformações da paisagem...” (CLAVAL, 1999, p. 40).

Assim, esse reducionismo e "a inadaptação do conceito de gênero de vida à análise dos meios urbanizados e industrializados" (CLAVAL, 1999, p. 48) podem ser considerados como alguns dos fatores da crise da geografia cultural, em meados do século $\mathrm{XX}$.

A crise da geografia cultural (que se prenunciava como profunda e duradoura, nas décadas de 1950 a 1970, principalmente levando-se em conta o sucesso dos novos paradigmas neopositivista e neomarxista), na verdade dura pouco. Um forte movimento de reconstrução da geografia cultural já se desenvolve a partir do início dos anos 1970, em países anglo-saxões e na França, dos quais esse movimento se difunde para o restante do mundo*.

Entre os temas privilegiados pela denominada "nova geografia cultural", o sentido dos lugares e a literatura aparecem, para Claval (1999, p. 55 e 56), como alguns dos mais dinâmicos e promissores, sem abandonar (muito longe disso!), o clássico tema da paisagem.

$\mathrm{Na}$ verdade, sem chegar a caracterizar-se como um paradigma no sentido kuhniano original, a geografia cultural aparece, neste início do século XXI, como uma alternativa válida em relação às correntes epistemológicas ainda dominantes na geografia. $\mathrm{O}$ fato de ter praticamente funcionado como um forte fator unificador para as orientações da percepção, da cognição e da representação do ambiente e das paisagens, vem reforçar o papel protagônico das abordagens culturais para a geografia e outros campos do conhecimento atual.

Para a finalidade do presente ensaio, a importância das literaturas na nova geografia cultural é a questão primordial.

\section{A GEOGRAFIA E AS LITERATURAS DE EXPLORAÇÃO, VIAGENS E AVENTURAS}

Possivelmente, os relatos de viagens - em todos os seus formatos: narrações orais, relatórios

\footnotetext{
* Na França, além do próprio Paul Claval, alguns nomes se destacam nessa reconstrução: A. Frémont, J. Bonnemaison, J.-R. Pitte, M. Serres, J.-M. Besse, A. Berque, M. Chevalier, J.-L. Piveteau, J.-P. Raison, A. Roger, entre outros.

No Brasil, podem ser citados, entre muitos outros: R. L. Corrêa, Z. Rosendahl, W. Holzer, S. Kozel, S. F. Gil Filho, S. T. de Lima, L. Bley, A. Serpa, W.-D. Sahr, L. M. C. Ph. Machado, I. A. de Vargas, J. C. Silva, Y. Nakagawara, E. Marandola...
} 
escritos, diários, croquis e outros desenhos, fotografias, etc - tenham sido, desde os tempos mais remotos da história humana, uma das principais fontes da geografia.

As viagens, explorações e aventuras, independentemente ou não de finalidades científicogeográficas, respondem a algumas necessidades naturais do ser humano: curiosidade, espírito de aventura, gosto pelo enfrentamento de riscos, etc...

Por essas razões, as viagens de explorações e aventuras têm gerado, ao longo da história humana, dois grandes conjuntos de literaturas complementares cujas fronteiras nem sempre são claras:

- um conjunto mais numeroso de obras, em que o ramanesco é a finalidade maior, embora se utilize das descrições geográficas de itinerários, regiões, lugares e paisagens como contextos ou cenários indispensáveis para seus enredos;

- um outro conjunto de trabalhos, para os quais os itinerários, regiões, lugares e paisagens são os próprios objetivos, caracterizando-se como estudos mais científicos e geográficos.

De maneira esquemática, pode-se levantar a hipótese, segundo a qual, em seus primórdios na Grécia antiga, uma parte do conhecimento geográfico surgiu como contexto e cenário para obras literárias de ficção, que tinham a difusão de valores morais e estéticos (para a educação do cidadão grego) como principal objetivo. Nesses "cenários geográficos", as descrições mesclavam informações fidedignas resultantes de observações diretas e relatos elaborados com método e equilíbrio, com impressões do insólito e do exótico, que valorizavam ainda mais o extraordinário. Obras clássicas de literatura de viagens e aventura, como A Odisséia de Homero, ou Os Argonautas de Apolônio de Rodes, exemplificam essa literatura. Porém, mais avançada na antiguidade grega, a descrição geográfica evolui para servir de contexto ou cenário da história (como em Heródoto), ou assume a finalidade maior de conhecimento mais racional do ecúmeno (como em Estrabon), já no tempo do Império Romano. Se, em Heródoto, ainda se encontram informações geográficas um tanto inverossímeis, em Estrabon, elas são mais raras, como resultado do espírito mais exigente e crítico deste último.

Com o fim do Império Romano, e a fragmentação econômica, política e cultural que ocorre nos primeiros séculos da Idade Média, o insólito, o exótico e o extraordinário voltam a povoar os relatos de viagem, mesmo aqueles que assumem uma postura formalmente geográfica. O Livro das Maravilhas, de Marco Pólo, com todo o significado que tem para a geografia e mesmo tendo sido elaborado em um período já avançado da Idade Média, está cheio de relatos e referências inverossímeis e extraordinários.

Na Idade Média, além de Marco Pólo, outros viajantes ocidentais que deixaram relatos estiveram quase sempre ligados a motivações religiosas, como as Cruzadas e as Peregrinações.

Dentro deste mesmo período, porém filiados a uma outra matriz religiosa e civilizacional, alguns grandes viajantes exploraram extensos itinerários, cidades e regiões do mundo islâmico. Al-Idrisi (ou simplesmente Edrisi) e, especialmente, Ibn-Battuta são os dois exploradores mais citados pelos historiadores do pensamento geográfico. E, de fato, ambos deixaram extensos relatos de longas viagens, hoje transformados em livros publicados em países do Ocidente.

Com o fim da Idade Média, as grandes navegações oceânicas, a descoberta e o início das explorações intracontinentais, o horizonte geográfico e o ecúmeno se ampliam espetacularmente. Cartógrafos e exploradores se multiplicam de tal maneira que a citação de uma proporção, mesmo significativa, deles cometerá o pecado do esquecimento de nomes importantes.

Imperialismo, colonialismo, proselitismo religioso, desenvolvimento do conhecimento científico, curiosidade em relação ao insólito e ao 
exótico, busca de glória e de aventura, tais são algumas das motivações que conduziram os europeus a assumirem do século XVI ao século XIX, a liderança das viagens de exploração e aventuras.

Nesse sentido, o século XIX parece ser o apogeu de todo o tipo de expedições para o melhor conhecimento do mundo. Além isso, é certamente o momento histórico de maior prestígio para a já antiga atividade geográfica, que atinge o status de disciplina acadêmica, status este que, a partir da Europa, se generaliza rapidamente por quase todo o mundo.

Metrópoles, ministérios, quartéis-generais, matrizes de grandes empresas, igrejas, sedes de jornais e editoras, departamentos acadêmicos e, sobretudo, sociedades geográficas estão na raiz deste século de explorações.

\section{VIAGENS, EXPLORAÇÕES, AVENTURAS E LITERATURA NO SÉCULO XIX}

Em uma edição comemorativa de "1.000 anos de ciência", o periódico francês Les Cahiers de Science et Vie inicia seu número 50, de abril de 1999, com as seguintes afirmações:

a) "No início do século XIX, os Europeus controlam $35 \%$ das superfícies emersas do planeta. Cem anos mais tarde, 1914, a proporção atinge 84\%" (GODOC, 1999, p. 5).

b) "Para levar a bom termo o inventário de suas possessões, e para fazê-las produzir os indispensáveis recursos reclamados pela industrialização, uma e outra (ciência e tecnologia), por intermédio de suas instituições, organizam vastas redes de estudiosos. (...) Elas são destinadas a tornar conhecidas as terras visitadas, a fim de suscitar o interesse do público pela expansão colonial e no que diz respeito a trabalhos tanto de botânica, de zoologia, de geografia, quanto da etnologia" (GODOC, 1999, p. 3).

A colocação em prática das intenções acima referidas só se concretizou no século XIX, com a criação de vários departamentos e laboratórios de botânica, zoologia, geografia, etnologia, geologia, etc, nas principais universidades dos países metropolitanos europeus.

Um papel tanto ou mais importante na promoção e no patrocínio de expedições e viagens de exploração foi desempenhado pelas sociedades geográficas, criadas em vários países, sobretudo europeus, a partir do ano de 1821 .

Para se ter uma idéia do entusiasmo dos franceses com as viagens de exploração geográfica naquela época, basta acrescentar que, incluindo a de Paris, foram criadas em cidades grandes e médias da França, durante o século XIX, nada menos do que trinta e cinco sociedades geográficas.

É significativo assinalar que a quase totalidade dos viajantes exploradores europeus do século XIX e do início do século XX pertencia às sociedades geográficas, eram, total ou parcialmente, patrocinados por elas e, ao retornarem, apresentavam seus resultados, relatos orais e relatórios escritos, às assembléias dessas sociedades.

O material assim acumulado constituiu um acervo inestimável, tanto para os interesses das grandes metrópoles européias, quanto para instituições científicas e culturais e para pesquisadores, aventureiros, empresas jornalísticas e grandes editoras.

O impacto dessa ampliação sem precedentes do horizonte geográfico, levando ao que se chamou de "século de ouro da geografia", também se fez fortemente sentir no domínio da literatura.

A busca do conhecimento, da experiência e de sentimentos de simpatia, admiração, ou aversão por itinerários, regiões, paisagens e lugares desconhecidos e, sobretudo, exóticos reflete-se no desenvolvimento de uma variada e rica literatura.

A título de exploração bem inicial, e considerando-se que se trata de uma tentativa 
taxonômica de um simples geógrafo, sem formação sólida nos estudos sobre literatura, o quadro seguinte procura fornecer uma classificação tipológica exploratória de algumas manifestações da literatura européia ligada às viagens no século XIX.

O que poderia chamar a atenção de leitores e admiradores das obras gigantescas do francês Júlio
Verne e do alemão Karl May*, é o fato dos dois escritores conseguirem conciliar romances e aventuras de grande apelo literário para os jovens e leitores de todas as idades, com a presença de conhecimento geográfico de ponta para a época, sobre os itinerários, regiões, cidades, lugares e paisagens que contextualizam os heróis e as tramas de suas obras.

Quadro 1 - Lista das sociedades de geografia de alcance internacional, criadas no século XIX

\begin{tabular}{|c|c|}
\hline $\begin{array}{l}\text { - } 1821: \text { Paris (Société } \\
\text { - } 1830: \text { Londres (Roy } \\
\text { - } 1836: \text { Francfort sur } 1 \\
\text { - } 1852: \text { New York } \\
\text { - } 1863: \text { Genève } \\
\text { - } 1867: \text { Kiesde } \\
\text { - } 1870: \text { Brême } \\
\text { - } 1873: \text { Rome } \\
\text { - } 1873: \text { Amsterdam } \\
\text { - } 1873: \text { Halle } \\
\text { - } 1875: \text { Bucarest } \\
\text { - } 1875: \text { Lisbonne } \\
\text { - } 1876: \text { Bruxelles } \\
\text { - } 1876: \text { Lima } \\
\text { - } 1877: \text { Stockholm } \\
\text { - } 1877: \text { Québec } \\
\text {. Tokvo }\end{array}$ & $\begin{array}{l}\text { - } 1828: \text { Berlin } \\
\text { - } 1833: \text { Mexico } \\
\text { - } 1845: \text { Saint-Pétersbourg } \\
\text { - } 1856: \text { Vienne } \\
\text { - } 1861: \text { Leipzig } \\
\text { - } 1867: \text { Turin } \\
\text { - } 1869: \text { Munich } \\
\text { - } 1872: \text { Budapest } \\
\text { - } 1873: \text { Berne } \\
\text { - } 1873: \text { Hambourg } \\
\text { - } 1875: \text { Copenhague } \\
\text { - } 1875: \text { Madrid } \\
\text { - } 1875: \text { Le Caire } \\
\text { - } 1876: \text { Anvers } \\
\text { - } 1876: \text { Alger } \\
\text { - } 1877: \text { Varsovie } \\
\text { - } 1878: \text { Hanovre } \\
\text { - } 1883: \text { Rio de Janeiro } \\
\text { - } 1888: \text { Washingtel } \\
\text { - } 1888: \text { Sydney } \\
\text { - } 1891: \text { Philadelphie } \\
\text { - } 1898: \text { Chicago } \\
\text { - } 1899: \text { Dacca } \\
\end{array}$ \\
\hline
\end{tabular}

Fonte: Site da Société de Géographie de Paris, 2008.

\footnotetext{
* Entre cujos leitores, o autor do presente ensaio se inclui de maneira incondicional.
} 
Literatura de explorações e aventuras: as "viagens extraordinárias" de Júlio Verne Oswaldo Bueno Amorim Filho

Quadro 2 - Alguns tipos de literaturas ligadas às viagens, na Europa do século xix

DO ROMANESCO $\longrightarrow$ AO CIENTÍFICO

\begin{tabular}{|c|c|c|c|c|}
\hline $\begin{array}{l}\text { a) } \underline{\text { Romances }} \\
\text { essencialistas, } \\
\text { realistas, intimistas, } \\
\text { de costumes, } \\
\text { marcados por uma } \\
\text { acuidade psicológica, } \\
\text { nos quais o meio, a } \\
\text { natureza, as viagens, } \\
\text { as paisagens têm uma } \\
\text { função contextual } \\
\text { apenas. Exemplo: } \\
\text { BALZAC }\end{array}$ & $\begin{array}{l}\text { b) } \text { Romances de } \\
\text { viagens, exotismos, } \\
\text { imaginação, } \\
\text { sensibilidade, lirismo } \\
\text { pessoal, admiração } \\
\text { das paisagens } \\
\text { grandiosas, } \\
\text { religiosidade. } \\
\text { Filiação ao } \\
\text { Romantismo. } \\
\text { Exemplo: } \\
\text { CHATEAUBRIAND }\end{array}$ & $\begin{array}{l}\text { c) } \underline{\text { Romances }} \\
\text { geográficos de } \\
\text { exploração e de } \\
\text { aventuras, fiéis às } \\
\text { realidades } \\
\text { geográficas, às vezes } \\
\text { mescladas ao insólito } \\
\text { e ao exótico. Caráter } \\
\text { educativo e ético. } \\
\text { Exemplos: VERNE e } \\
\text { MAY }\end{array}$ & $\begin{array}{l}\text { d) Relatos de } \\
\text { viagens de } \\
\text { exploração, com } \\
\text { informações e } \\
\text { cartografia obtidos } \\
\text { no campo. Presença } \\
\text { de romantismo e } \\
\text { riscos. Ligados às } \\
\text { Sociedades } \\
\text { Geográficas. } \\
\text { Exemplos: } \\
\text { BURTON e } \\
\text { SAINT-HILAIRE }\end{array}$ & $\begin{array}{l}\text { e) Geografia de } \\
\text { campo e viagens. } \\
\text { Métodos, técnicas } \\
\text { e instrumentos } \\
\text { científicos. } \\
\text { Relatórios para a } \\
\text { universidade. } \\
\text { Obras acadêmicas. } \\
\text { Exemplo: } \\
\text { HUMBOLDT }\end{array}$ \\
\hline
\end{tabular}

- Organizado por Oswaldo Bueno Amorim Filho (PUC-Minas/2008)

\section{JÚLIO VERNE: LITERATO OU GEÓGRAFO?}

O que se verificou, especialmente em relação à obra de Júlio Verne (objeto deste estudo) é algo surpreendente, inesperado e paradoxal. Ainda tendo como referência o quadro 2, ocorreu que, de um lado, estudiosos e críticos da literatura, em sua maioria e até poucas décadas atrás, preferiram se concentrar em temas e autores tais como os tipificados nas células a e $\mathrm{b}$, enquanto que, de outro lado, a maior parte dos historiadores do pensamento geográfico acharam mais interessante e confortável explorarem temas e autores semelhantes aos que foram tipificados nas células de e.

Em função desta postura, na melhor das hipóteses comodista, Júlio Verne (o mais traduzido dos escritores franceses e aquele cujos livros estão entre os que mais têm gerado peças teatrais, filmes e programas para a televisão) não tem sido reconhecido na literatura francesa e tem sido mal recebido na geografia daquele país.

No que diz respeito à literatura, sempre causou espanto que o volume da Collection Littéraire Lagarde \& Michard, consagrado ao século XIX (edição de 1969), não faça a menor referência à obra de Júlio Verne. É importante mencionar que se trata de uma coleção em seis volumes, que se colocou, por muitos anos, entre as obras mais lidas e consultadas pelos estudantes estrangeiros da língua francesa. Como seria possível que uma obra com as dimensões daquela de Verne pudesse ficar "invisível”, em uma coleção como a de Lagarde \& Michard?

O mais incrível é que no volume IV, da famosa "Collection G. Mauger" (edição de 1957), patrocinada pela própria Alliance Française, entre mais de uma centena de autores, que tiveram pequenos textos reproduzidos no referido volume IV, também não se faça nenhuma referência a Júlio Verne.

É bem verdade que o ostracismo a que foi submetida a obra de Júlio Verne, por certos críticos literários, vem sendo rompido, principalmente nos últimos quarenta anos. Em 1969, por exemplo, a Editora Documento Ltda, de São Paulo, traduziu e publicou uma coletânea francesa, que continha treze artigos inteiramente voltados para a obra de Júlio Verne, do ponto de vista literário. O que resulta da leitura deste livro, no qual colaboram intelectuais franceses 
consagrados como M. Foucault, M. Serres e M. Butor, entre outros, é o reconhecimento de qualidades e defeitos dos escritos de J. Verne, enquanto obra literária. Para Michel Serres, por exemplo:

"De fato, sempre se trata de explorações e de descobertas, de viagens que permitem ver melhor as coisas, de itinerários para conhecer o desconhecido. (...) Mas, em sua intenção, a tradição homérica é respeitada: instruir e agradar, fazer o balanço das ciências e das técnicas de seu tempo; ir além das terras conhecidas e dos conhecimentos humanos. Divertir, ensinar, iniciar. É enfim e sobretudo uma Viagem Iniciatória, sob o mesmo aspecto do périplo de Ulisses, do Êxodo do povo hebreu ou do itinerário de Dante, (...) apesar das fraquezas artísticas e intelectuais de Verne" (SERRES, 1969, p. 25 e 26).

Bem mais recentemente, Michel Tournier, no prefácio para a reedição de $\mathbf{A}$ Jangada, faz uma leitura crítica original de toda a obra de Júlio Verne.

Michel Tournier, da Academia Goncourt, começa seu prefácio com a definição etimológica da geografia, ou seja "a escritura da Terra".

Em seguida, faz uma divisão "elementar e, mesmo, simplista" dos escritores em dois grupos distintos: "os escritores inspirados pela história e os escritores inspirados pela geografia".

Para Tournier, esta distinção remonta a um tempo bem distante, "pelo menos até Homero, escritor duplo pois que a Ilíada é uma lenda histórica, enquanto a Odisséia é uma epopéia geográfica" (TOURNIER, 2005, p.9).

Tournier prossegue, afirmando que "o maior escritor geógrafo da literatura francesa é, com certeza, Júlio Verne" (TOURNIER, 2005, p.9).

Se, para uma parte significativa de críticos literários e mesmo de escritores, a obra de Júlio Verne (mesmo lida por todos eles!) é negligenciada, sua posição entre os geógrafos não é mais confortável.
Em um balanço brevíssimo de alguns textos já consagrados sobre a história do pensamento geográfico na França, naquilo que se refere ao papel de Júlio Verne enquanto geógrafo, os resultados obtidos foram os seguintes:

- A. Meynier (1969) faz uma pequena referência a Júlio Verne, enquanto se serve de uma citação de Vivien de Saint-Martin, que analisa a fragilidade das publicações geográficas voltadas para a educação dos franceses, antes de 1872:

Todos os livros em uso, "são intermináveis nomenclaturas, áridos e repelentes exercícios de memória, nada que fale ao espírito e solicite a inteligência" (1866). Saint-Martin só consegue citar dois tipos de boas obras: as Lectures Géographiques de Raffy (coletânea de textos tomados emprestados sobretudo a exploradores e viajantes, obra efetiva-mente notável para a época...); e os romances de Júlio Verne" (MEYNIER, 1969, p. 8);

- René Clozier (1972): não há referência a Júlio Verne;

- Ph. Pinchemel (1984): embora a volumosa obra organizada por Pinchemel seja um dos poucos trabalhos de cunho epistemológico a incluir Júlio Verne entre os geógrafos franceses anteriores a 1890, a apresentação que dele faz J.-L. Tissier tem um sentido predominantemente pejorativo:

"Júlio Verne foi membro da Société de Géographie por mais de 40 anos. Mas, sua contribuição ao conhecimento geográfico é reduzida. A matéria geográfica de suas obras é sempre de segunda mão e suas viagens foram muito comuns. Sua fonte essencial foi a geografia tradicional descritiva" (TISSIER, 1984, p. 55)

- V. Berdoulay (1995), em suas reflexões sobre "a formação da escola francesa de geografia", faz duas pequenas referências a Júlio Verne: - a primeira, quando se volta para a escola 
francesa anterior a 1870 e para o ensino de acordo com a ideologia republicana, chamando a atenção para "a colaboração ativa do prof. Jean Mace e de Júlio Verne" em uma revista educativa criada pelo editor P.J. Hetzel (BERDOULAY, 1995, p. 78);

- a segunda, quando faz referência ao periódico Le Tour du Monde, criado pelo editor Louis Hachette, em 1860, e "que devia alcançar um vasto público e suscitar a curiosidade geográfica do leitor" (BERDOULAY, 1995, p. 78). No rodapé desta mesma página, Berdoulay diz que "a orientação literária da revista era verdadeiramente aquela de um de seus colaboradores, Jules Verne. Este escreveu também uma importante obra não romanceada: Géographie ilustrée de la France et de ses colonies. Paris, J. Hetzel, 1867-68, 2 vol." (BERDOULAY, 1995, p. 143).

- P. Claval (1995): não há referência a Júlio Verne.

\section{ALGUMAS CONSIDERAÇÕES EXPLORATÓ- RIAS SOBRE A GEOGRAFIA NA OBRA DE JÚLIO VERNE}

Para quem, com o espírito infantil ou no começo da adolescência, fez uma leitura apenas para o divertimento e o prazer, de alguns livros traduzidos e condensados de Júlio Verne, sua redescoberta atual - com o olhar amadurecido por mais de sessenta anos de vida e quarenta e um de pesquisas e reflexões geográficas - é algo extraordinário, sem deixar de ser prazeroso.

$\mathrm{Se}$, do ponto de vista romanesco e da aventura, os sentimentos do leitor ganham relevos menos ingênuos, no que diz respeito à presença da geografia, as descobertas e admiração ganham dimensões antes inimagináveis.

Antes de avançar mais é preciso tomar consciência de dois gigantismos.

O primeiro é que, para fazer as descrições dos itinerários e rotas, assim como dos oceanos, continentes, países, regiões, cidades, acidentes geográficos, lugares e paisagens, onipresentes em toda a obra, os estudos e a assimilação dos conhecimentos geográficos, geológicos, biológicos e etnológicos disponíveis no século XIX europeu só podem ter sido exaustivos, sem resvalar para a superficialidade. Só um acompanhamento permanente de quase tudo que se produzia em termos de pesquisa geográfica pode explicar o volume de conhecimentos geográficos e afins presentes nos livros de Verne. A fundamentação disto está nas leituras que Júlio Verne fez dos relatos de viagens de Humboldt, ou da geografia universal de Reclus, assim como dos relatórios de dezenas de viajantes exploradores, entre os quais podem nomearse: Burton, Speke, Livingstone, Stanley, Orellana, La Condamine, Agassiz, Crévaux, Chaffanjon, Durand, Lister-Maw, Sweathman, Tasman, Vivien de SaintMartin, Lejeanne, De Bono, Rousselet, entre outros.

O segundo diz respeito às dimensões da própria obra de Júlio Verne. A leitura mais universal de apenas alguns best-sellers famosos pode dar uma impressão errônea. Embora haja alguma divergência sobre quantos livros publicou Júlio Verne, sobretudo se se levar em conta que manuscritos desconhecidos têm sido descobertos e publicados nos últimos anos, sabe-se que sua produção literária foi imensa.

Daniel Compère, que publicou recentemente (2005) uma biografia e uma análise crítica da obra de Júlio Verne, faz uma listagem de 80 livros como pertencentes à coleção verniana das Voyages Extraordinaires.

Na vasta obra de Júlio Verne, a geografia está sempre presente em várias de suas manifestações e não é incomum que geógrafos e/ou naturalistas sejam personagens cuja ação aparece como decisiva em grande parte das viagens extraordinárias. Assim, Júlio Verne não apenas faz parte de uma época na qual a geografia já goza de grande prestígio mas, também, aparece como um dos escritores que mais contribuíram para aumentar consideravelmente esse interesse na França e no mundo. 
Quadro 3 - Os volumes das "voyages extraordinaires"

(1) 1851. LES PREMIERS NAVIRES DE LA MARINE MEXICANE. L'AMÉRIQUE DU SUD. ÉTUDES HISTORIQUES

(2) 1851. UN VOYAGE EN BALLON. LA SCIENCE EN FAMILLE

(3) 1852. MARTIN PAZ. L'AMÉRIQUE DU SUD. MOEURS PÉRUVIENNES

(4) 1854. MAÎTRE ZACHARIUS ou L'HORLOGER QUI AVAIT PERDU SON ÂME

(5) 1855. UN HIVERNAGE DANS LES GLACES

(6) 1863. CINQ SEMAINES EN BALLON

(7) 1864-65. VOYAGES ET AVENTURES DU CAPITANE HATTERAS

(8) 1864. VOYAGE AU CENTRE DE LA TERRE

(9) 1865. DE LA TERRE À LA LUNE. TRAJET DIRECT EN 97 HEURES

(10) 1865. LES FORCEURS DE BLOCUS. ETUDES DE MOEURS CONTEMPORAINES

(11) 1866-67. LES ENFANTS DU CAPITAINE GRANT

(12) 1869-70. VINGT MILLE LIEUES SOUS LES MERS

(13) 1869. AUTOUR DE LA LUNE

(14) 1870. UNE VILLE FLOTTANTE

(15) 1871-72. AVENTURES DE TROIS RUSSES ET DE TROIS ANGLAIS DANS L'AFRIQUE AUSTRALE

(16) 1872. UNE FANTAISIE DU DOCTEUR OX

(17) 1872-73. LE PAYS DES FOURRURES

(18) 1872. LE TOUR DU MONDE EN QUATRE-VINGTS JOURS

(19) 1874-75. L'ÎLE MYSTÉRIEUSE

(20) 1874. LE DOCTEUR OX

(21) 1874-75. LE CHANCELLOR

(22) 1876. MICHEL STROGOFF. DE MOSCOU À IRKOUTSK

(23) 1877. HECTOR SERVADAC. VOYAGES ET AVENTURES À TRAVERS LE MONDE SOLAIRE

(24) 1877. LES INDES NOIRES

(25) 1878. UN CAPITAINE DE QUINZE ANS

(26) 1879. LES CINQ CENTS MILLIONS DE LA BÉGUM

(27) 1879. LES TRIBULATIONS D'UN CHINOIS EN CHINE

(28) 1879. LES RÉVOLTÉS DE LA BOUNTY

(29) 1879-80. LA MAISON À VAPEUR. VOYAGE À TRAVERS L'INDE SEPTENTRIONALE

(30) 1881. LA JANGADA. HUIT CENTS LIEUES SUR L'AMAZONE

(31) 1882. L'ECOLE DES ROBINSONS

(32) 1882. LE RAYON VERT

(33) 1883. KÉRABAN-LE-TÊTU

(34) 1884. L'ETOILE DU SUD. LE PAYS DES DIAMANTS
(35) 1884. L'ARCHIPEL EN FEU

(36) 1884. FRRITT-FLACC

(37) 1885. MATHIAS SANDORF

(38) 1886. UN BILLET DE LOTERIE. LE NUMÉRO 9672

(39) 1886. ROBUR-LE-CONQUÉRANT

(40) 1887. NORD CONTRE SUD

(41) 1887. LE CHEMIN DE FRANCE

(42) 1887. GIL BRALTAR

(43) 1888. DEUX ANS DE VACANCES

(44) 1889. FAMILLE-SANS-NOM

(45) 1889. LA JOURNÉE D'UN JOURNALISTE AMÉRICAIN EN 2889

(46) 1889. SANS DESSUS DESSOUS

(47) 1890. CÉSAR CASCABEL

(48) 1891. AVENTURES DE LA FAMILLE RATON

(49) 1891. MISTRESS BRANICAN

(50) 1892. LE CHÂTEAU DES CARPATHES

(51) 1892. CLAUDIUS BOMBARNAC

(52) 1893. P'TIT-BONHOMME

(53) 1893. M. RÉ-DIÈZE ET MLLE MI BÉMOL

(54) 1894. MIRIFIQUES AVENTURES DE MAÎTRE ANTIFER

(55) 1895. L'ILE À HÉLICE

(56) 1896. FACE AU DRAPEAU

(57) 1896. CLOVIS DARDENTOR

(58) 1897. LES SPHINX DES GLACES

(59) 1898. LE SUPERBE ORÉNOQUE

(60) 1899. LE TESTAMENT D'UN EXCENTRIQUE

(61) 1900. SECONDE PATRIE

(62) 1901. LE VILLAGE AÉRIEN

(63) 1901. LES HISTOIRES DE JEAN-MARIE CABIDOULIN

(64) 1902. LES FRÈRES KIP

(65) 1903. BOURSES DE VOYAGE

(66) 1904. UN DRAME EN LIVONIE

(67) 1904. MAÎTRE DU MONDE

(68) 1905. L'INVASION DE LA MER

(69) 1905. LE PHARE DU BOUT DU MONDE

(70) 1906. LE VOLCAN D'OR

(71) 1907. L'AGENCE THOMPSON AND C ${ }^{\circ}$

(72) 1908. LA CHASSE AU MÉTÉORE

(73) 1908. LE PILOTE DU DANUBE

(74) 1909. LES NAUFRAGÉS DU "JONATHAN"

(75) 1910. LE SECRET DE WILHELM STORITZ

(76) 1910. L'ETERNEL ADAM

(77) 1910. HIER ET DEMAIN

(78) 1910. LA DESTINÉE DE JEAN MORÉNAS

(79) 1910. LE HUMBUG

(80) 1914. L'ETONNANTE AVENTURE DE LA MISSION BARSAC

Fonte: COMPÈRE, Daniel. Jules Verne - Parcours d'une oeuvre. Paris, Encrage, 2005, 172 p.

Para que a geografia não seja algo acessório em seus romances, Júlio Verne utiliza, com segurança e domínio, uma vasta terminologia geográfica e aplica, como o fariam os principais geógrafos da época, alguns conceitos e princípios fundamentais. Nessa profusão de conceitos e princípios, alguns são mais 
utilizados e demonstram que, ao contrário do que afirmam certos críticos, a geografia descritiva não é a única que o escritor francês desenvolve, e que ele está consciente dos avanços epistemológicos desta ciência.

Entre os grandes princípios da geografia, que só seriam sistematizados na primeira metade do século $\mathrm{XX}$, já podem ser identificados em Júlio Verne, quase sempre de maneira implícita, pelo menos os seguintes:

- princípio da conexão;

- princípio de causa e efeito;

- princípio da diferenciação de áreas;

- princípio da extensão;

- princípio da atividade.

Pelo menos duas orientações epistemológicas gerais da geografia européia de então, sobretudo na Alemanha, aparecem na obra de Verne. Trata-se da geografia comparada (ou comparativa), abordagem proposta por Carl Ritter, e dos vários tipos de influência que o ambiente natural exerce sobre os homens. Porém, a consciência em relação a este último aspecto não deve levar o leitor atento a pensar que Verne seja um adepto do determinismo natural. Muito ao contrário, pois, por sua crença na importância da ação humana, mediada por uma tecnologia cada vez mais sofisticada, Verne pode ser classificado entre os pioneiros da geografia humana que, só no final do século XIX, seria explicitada.

Entre os conceitos geográficos, que se identificam em todos os romances de Júlio Verne, os mais importantes são:
- posição (principalmente em relação aos fatores do ambiente natural e às grandes medidas da Terra, isto é, coordenadas, altitudes, etc);

- sítio (sempre em detalhe);

- distância (absoluta e relativa);

- gênero de vida (em quase todas as partes do mundo);

- região e zona;

- lugar (inclusive em seu sentido afetivo e simbólico);

- paisagem (em suas perspectivas física e humana).

Um último aspecto que, dentro das limitações do presente texto, merece atenção especial na obra de Júlio Verne é o papel primordial desempenhado pelos roteiros e itinerários seguidos por heróis e demais personagens de todos os romances. Pelo fato de serem muito numerosas essas viagens extraordinárias, praticamente todos os oceanos e todos os continentes foram visitados e tiveram regiões, paisagens e lugares geograficamente descritos.

Como se observa nas figuras (mesmo que elas representem apenas algumas das rotas seguidas por personagens vernianos), muitas das regiões descritas faziam parte de espaços pouco conhecidos ou totalmente desconhecidos, na segunda metade do século XIX e na primeira década do século XX.

Este aspecto é um daqueles que mais servem para comprovar o caráter educativo e humanista que Júlio Verne e seu editor Pierre-Jules Hetzel imprimiram a toda a coleção das "Voyages Extraordinaires". 
Figura 1

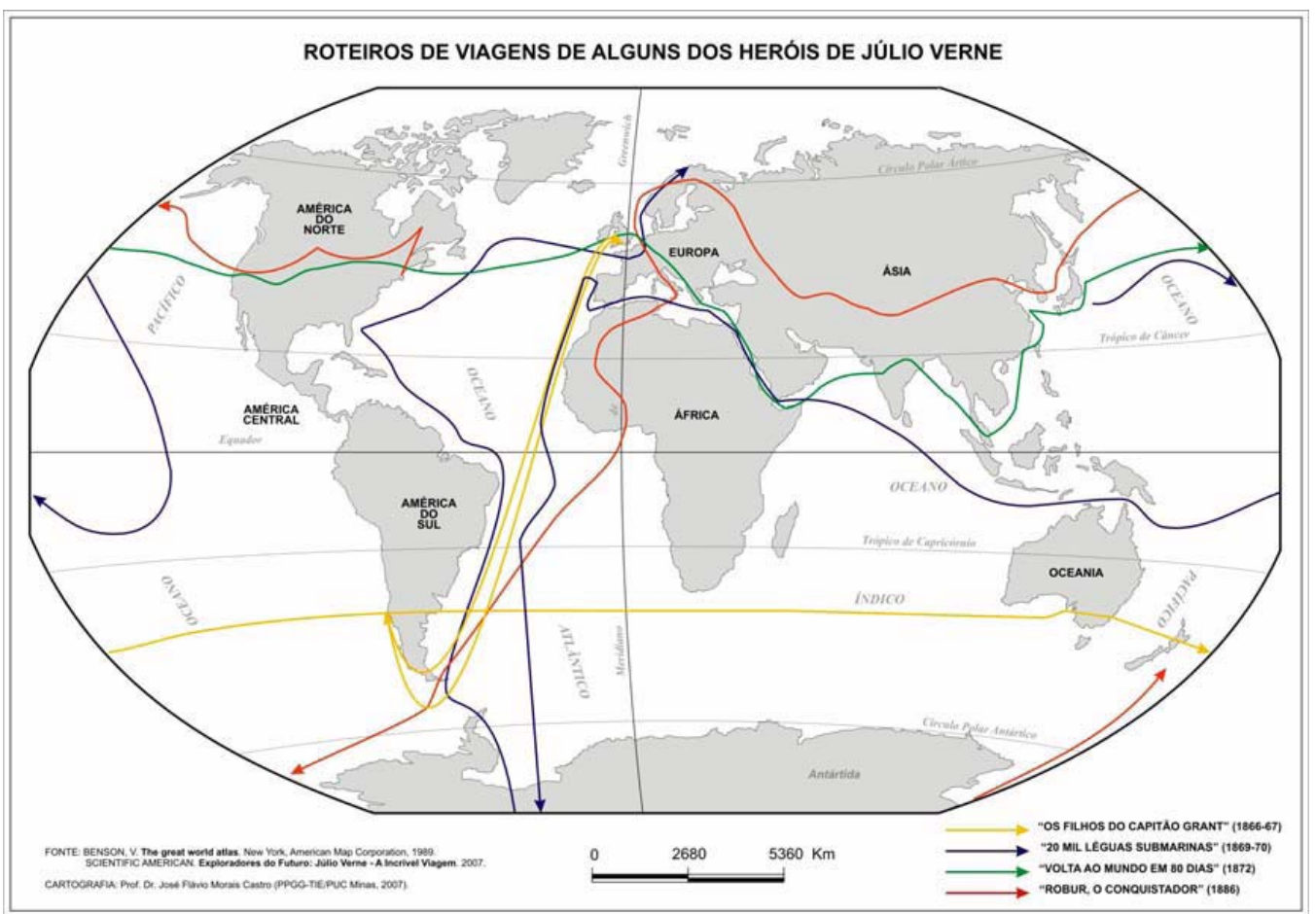

Figura 2

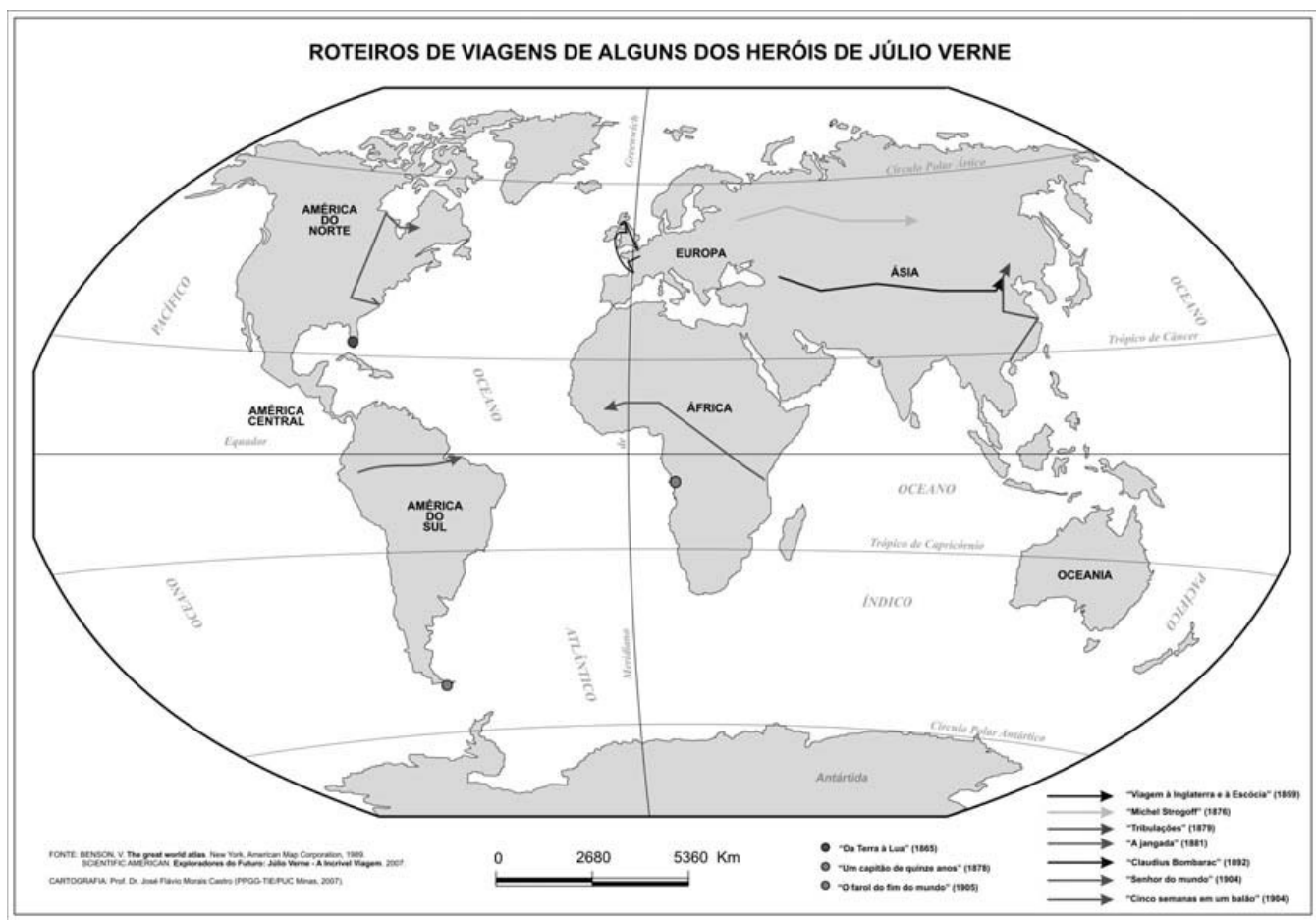

Sociedade \& Natureza, Uberlândia, 20 (2): 107-119, DEZ. 2008 


\section{CONSIDERAÇÕES FINAIS}

As breves e modestas reflexões desenvolvidas nas páginas precedentes não têm nenhuma pretensão de serem rigorosas, exaustivas, científicas ou inovadoras. Isto seria bem difícil, principalmente porque numerosos são os intelectuais, inclusive geógrafos, que se têm debruçado sobre a vastíssima obra de Júlio Verne.

Os motivos de meus estudos (que estão apenas começando!) sobre este homem e seus escritos têm a ver com sentimentos bem simples, embora de importância primordial para mim, nesta etapa de minha vida.

O motivo mais recente e que levou a uma primeira redação e à sua conclusão precoce foi a pressa em terminar um texto que permitirá levar à discussão, no Colóquio de Uberlândia sobre a História do Pensamento Geográfico, um tema como este. O motivo seguinte, também importante, tem a ver com o atendimento ao pedido de um jovem geógrafo amigo: o Prof. Eduardo Marandola.

O último e também o mais antigo dos motivos tem a ver com questões e opções bastante pessoais. Um retorno à obra de Júlio Verne é uma volta à infância e à idade juvenil, mas é, igualmente, um "reencontro" com um dos maiores responsáveis por minha escolha profissional pela geografia.

Assim, nesta releitura ampliada de parte da obra de Júlio Verne, uma primeira surpresa foi a constatação de quão geográfica ela é. Mesmo quando se trata de descrever alguma ação carregada de perigo e emoção, os aspectos geográficos estão, de algum modo, presentes. Qualquer leitor de Júlio Verne, independentemente de idade, gênero, condição sócioeconômica e nível de educação, terá, ao terminar sua leitura, melhorado em muito seu mapa mental de nosso mundo. Mas, o mais importante é que será, daí em diante, mais humano e solidário, tendo em vista os valores humanistas que perpassam todas as estórias de Júlio Verne. São valores republicanos, num tempo em que grande parte da Europa era monarquista. São valores democráticos, quando grande parte do mundo ainda vivia sob o jugo do autoritarismo. É uma posição claramente antiescravista, quando milhares de africanos ainda sofriam nas mãos dos mercadores de homens.

São valores de otimismo e de crença ativa no futuro da humanidade, antevisto por meio dos avanços tecnológicos constatados ou antecipados pela ficção científica presente em várias das tramas vernianas.

Por fim, em toda essa obra gigantesca, estão presentes valores que a sociedade individualista de hoje vem esquecendo rapidamente: aqueles da amizade, fidelidade, lealdade, do respeito, do cumprimento do dever e da palavra dada, da generosidade, do cavalheirismo e da honestidade.

Júlio Verne foi um literato, um geógrafo, um republicano, mas, acima de tudo, um educador.

\section{REFERÊNCIAS:}

BELLOUR R. \& BROCHIER J.-J. (org.): Júlio Verne - Uma literatura revolucionária. São Paulo, Editora Documentos Ltda, 1969, 120 p. (Tradução de T. C. Netto).

BERDOULAY Vincent: La formation de l'école française de géographie. Paris, C. T. H. S., 1995, 253p., p.78 e 143.

CLAVAL, Paul: A geografia cultural. Florianópolis, Editora da UFSC, 1999, 453 p. (Tradução de Luiz Fugazzola Pimenta e Margaretti de Castro Afeche Pimenta).

CLOZIER, René: Histoire de la géographie. Paris, P. U. F., 1972, 128p. (Collection Que sais-je?).

GODOC, Françoise: Un siècle de conquêtes. Les Cahiers de Science et Vie. Paris, $\mathrm{n}^{\circ}$ 50, avril 1999, p. 3 et 5 .

LAGARDE, André et MICHARD, L.: XIX Siècle - 
Les grands auteurs Français du Programme. Paris, Bordas, 1969, 577p.

MAUGER, Gaston: La France et ses écrivains - Vol. IV. Paris, Librairie Hachette, 1957, 522p.

MEYNIER, André: Histoire de la pensée géographique en France (1872-1969). Paris, P. U. F., 1969, 224, p.8.

PAUMIER, Jean-Yves: Jules Verne - Voyageur extraordinaire. Paris, Glemat - Société de Géographie de Paris, 2005, 226p.

PINCHEMEL, Philippe (org.): Deux siècles de géographie française. Paris, C.T.H.S., 1984, 263p.

SERRES, Michel: Geodésicas da Terra e do Céu. In: BELLOUR R. \& BROCHIER J.-J. (org.): Júlio Verne - Uma literatura revolucionária. São Paulo, Editora Documentos Ltda, 1969, 120 p. (Tradução de T. C. Netto). 